\title{
Nem todas as pericardites são idiopáticas
}

\author{
Pericarditis - not all are idiopathic
}

\author{
Canelas $\mathrm{C}^{1}$, Carvas $\mathrm{JM}^{2}$, Fontoura $\mathrm{I}^{3}$, Lemos $\mathrm{J}^{4}$ \\ ${ }^{1}$ Interna complementar do $4^{0}$ ano de Medicina Interna, Centro Hospitalar de Trás-os-Montes e Alto Douro, Portugal. ${ }^{2}$ Interno do Ano Comum, Centro \\ Hospitalar de Trás-os-Montes e Alto Douro, Portugal. ${ }^{3}$ Interna complementar do $4^{\circ}$ ano de Medicina Interna, Centro Hospitalar Tondela e Viseu, Portugal. \\ ${ }^{4}$ Assistentes de Medicina Interna, Centro Hospitalar Tondela e Viseu, Portugal
}

\section{Resumo}

Apresenta-se um caso clínico de pericardite por Mycobacterium tubercuIosis, que condicionou um estado de pré-tamponamento cardíaco. Apesar dos progressos dos últimos anos, Portugal continua a ser o único país da Europa Ocidental com uma taxa intermédia de infeção por Mycobacterium tuberculosis. A infeção é adquirida por via respiratória e pode disseminar-se e instalar-se em qualquer órgão durante a primoinfeção ou em outra qualquer altura em que haja imunodepressão do indivíduo. 0 atingimento pleural é o mais comum e o pericárdico é raro, representando apenas $1-2 \%$ dos doentes com tuberculose.

No presente caso clínico torna-se evidente a importância de uma abordagem sistematizada e holística dos doentes com pericardite durante a sua investigação etiológica.

Palavras chave: Pericardite, Mycobacterium tuberculosis, Pericardiocentese, Antituberculosos.

\section{Introdução}

A pericardite é um diagnóstico raro, representando $0,1 \%$ das admissões hospitalares. Reflete um processo inflamatório que atinge o pericárdio, com eventual acumulação de líquido na cavidade pericárdica ${ }^{1,2}$.

Determinar a etiologia da pericardite é sempre um desafio. A maioria é idiopática, seguindo-se as causas neoplásica e infeciosa ${ }^{3}$. Relativamente à última etiologia, a incidência dos diferentes agentes infeciosos varia significativamente de acordo com a população em estudo, nomeadamente com a prevalência de doentes imunocomprometidos e em particular com a de VIH positivos. De uma maneira geral, os vírus são os mais comummente implicados, seguidos pelas bactérias e muito mais raramente fungos e parasitas. Dentro das bactérias, o Mycobacterium tuberculosis (MT) é o agente etiológico mais comum (4-5\%) $)^{1,3,4}$. Nas populações de doentes com VIH, a pericardite por MT é mesmo a etiologia mais comum, ultrapassando até a idiopática ${ }^{3,5}$.

Portugal continua a ser o único país da Europa Ocidental com uma taxa intermédia de infeção por MT ${ }^{6}$. A infeção por MT é adquirida por via respiratória e pode disseminar-se e instalar-se em qualquer órgão durante a primoinfeção ou em outra qualquer altura em que haja imunodepressão do indivíduo. 0 atingimento pleural é 0 mais comum e o pericárdico é raro, representando apenas 1-2\% dos doentes com tuberculose $e^{7,8}$.

A tuberculose pericárdica (TP) é uma patologia de difícil e frequentemente tardio diagnóstico, potenciando 0 aparecimento de complicações graves, das quais a mais frequente

\begin{abstract}
We report an interesting case of tuberculous pericarditis that evolved to a cardiac pre-tamponade. Portugal is still the only country in Western Europe with an intermediate rate of Mycobacterium tuberculosis infection. The infection is acquired by inhalation and can disseminate to any body organ during primary infection or at any other time where there is immunodepression of the patient. Pleural involvement is the most common and pericardial involvement is rare with just $1-2 \%$ of the patients with pulmonary tuberculosis.

In this clinical case we evidence the importance of a systematized approach to these patients during the etiological investigation.

Key-Words: Pericarditis, Mycobacterium tuberculosis, Pericardiocentesis, antituberculosis chemotherapy.
\end{abstract}

e ameaçadora da vida é a pericardite constritiva. No presente caso clínico torna-se evidente a importância de uma abordagem sistematizada e holística dos doentes com pericardite durante a sua investigação etiológica.

\section{Caso clínico}

Caucasiano do sexo masculino, 52 anos de idade. Antecedentes pessoais de hipertensão arterial, úlcera gástrica, distúrbio de ansiedade e taquicardia sinusal, medicado cronicamente com mexazolam. Negava hábitos tabágicos ou alcoólicos, bem como consumo de tóxicos por via endovenosa. Tinha relações sexuais com parceira única, sem uso de preservativo.

Recorreu ao Serviço de Urgência (SU) por queixas de desconforto torácico, tosse seca e dificuldade respiratória associadas a cefaleias, febre $\left(39-40^{\circ} \mathrm{C}\right)$, sem perfil horário particular e com fraca resposta aos antipiréticos e hipersudorese de predomínio noturno. Este quadro, com duas semanas de evolução, agravara-se nos 2 dias anteriores, apesar de um ciclo de antibioterapia. 0 desconforto torácico era retroesternal, sem irradiação nem relação com a ingestão alimentar; agravava com a inspiração e com o decúbito dorsal e aliviava com a anteversão do tronco. Referia também palpitações (desde longa data, relacionadas com eventos de stress emocional) bem como astenia e anorexia mais recentes (não sabia precisar) mas sem perda ponderal objetivável.

No exame físico, o doente estava hipotenso, taquicárdico e febril $\left(38,5^{\circ} \mathrm{C}\right)$. À auscultação cardíaca: sons cardíacos hipofonéticos, rítmicos, sem desdobramentos ou sopros audíveis e sem atrito pericárdio audível. Era também evidente turgescência venosa jugular a $45^{\circ}$.

Dos exames auxiliares de diagnóstico realizados na admissão, é de salientar: eletrocardiograma (ECG) com taquicardia sinusal e baixa voltagem; radiografia do tórax (RxT) com aumento do índice 
Figura 1. Radiografia do tórax evidenciando um aumento do ICT muito significativo em relação a exames anteriores e apagamento dos ângulos costofrénicos.

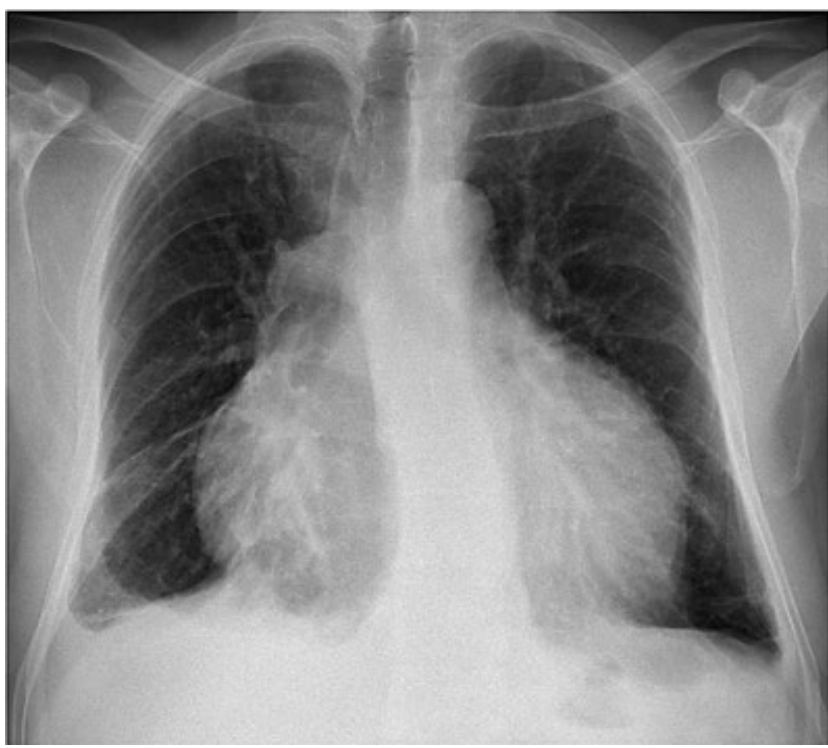

cardiotorácico (ICT) e apagamento dos ângulos costofrénicos (Figura 1); analiticamente, com anemia normocítica e normocrómica, aumento de parâmetros inflamatórios; ecocardiograma transtorácico com derrame pericárdico circunferencial com $23 \mathrm{~mm}$ na parede posterior, $25 \mathrm{~mm}$ na parede anterior e $27 \mathrm{~mm}$ na parede lateral associado a abaulamento da aurícula direita (AD) e com sinais de dificuldade de enchimento do ventrículo direito (VD). Mostrava também variabilidade respiratória transmitral, veia cava inferior (VCI) dilatada, sem excursão com os movimentos respiratórios (Figura 2). Tratava-se então de uma pericardite com derrame pericárdico a condicionar um estado de pré-tamponamento cardíaco. Procedeu-se a uma pericardiocentese com saída de $1000 \mathrm{~mL}$ de líquido sero-hemático com características bioquímicas de exsudado (critérios de Light).

Tratando-se de um doente imunocompetente e sem antecedentes pessoais de relevo, foi difícil inicialmente direcionar o estudo complementar. Considerando a gravidade da apresentação clínica, projetou-se um estudo alargado a todas as causas mais comuns de pericardite: infeciosa (vírica e bacteriana), neoplásica e autoimune (esta menos provável atendendo ao sexo e idade do doente). Dos exames complementares, salientamos: anemia de tipo inflamatório; serologias negativas para vírus (Coxsackie $A$ e $B$, hepatite B e C, grupo TORCH (Toxoplasma, Rubéola, Herpes), VIH 1 e 2 e Epstein-Barn) e para Coxiella, Brucella e Sífilis; hemoculturas negativas; pesquisa de ADN para Mycobacterium tuberculosis (MT) no sangue negativa; adenosina desaminase (ADA)no soro 37,4 $\mathrm{UI} / \mathrm{L}$, ligeiramente aumentada; marcadores tumorais apenas com discreta elevação do CA 125; estudo de autoimunidade sem alterações. Foi realizada tomografia computorizada (TC) toraco-abdomino-pélvica que revelou derrame pericárdico moderado, mais significativo no bordo cardíaco direito e com aspeto relacionado com patologia infeciosa/inflamatória; derrame pleural bilater e múltiplas adenopatias mediastínicas; formações ganglionares axilares e inguinais; aspetos de hipertrofia prostática; e achado de imagem sugestiva de nódulo no lobo direito da tiróide com 26mm. A investigação foi nesta altura direcionada para a pesquisa de uma
Figura 2. Ecocardiograma transtorácico, em corte apical 4-câmaras evidenciando derrame pericárdico severo circunferencial. D - Direita, E Esquerda.

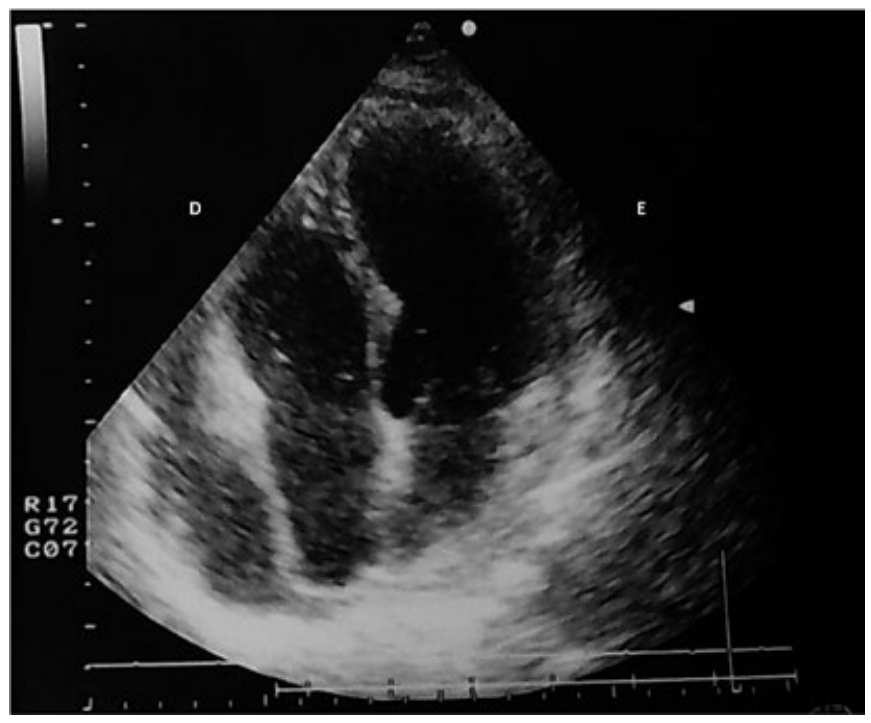

neoplasia primária a condicionar derrame pericárdico paraneoplásico. A ecografia cervical não mostrou formações nodulares tiroideias, adenopatias ou outras alterações de relevo. 0 toque retal e a ecografia prostática, acrescidos de um valor de PSA normal, excluíram neoplasia prostática. A endoscopia digestiva alta não evidenciou alterações de relevo. 0 estudo anátomo-patológico do líquido pericárdico revelou células mesoteliais reativas, linfócitos (30\% do total celular) e eritrócitos, sem células neoplásicas identificáveis. 0 exame histológico de uma adenopatia inguinal, submetida a biopsia excisional, mostrou linfadenite reativa inespecífica. Após 15 dias de internamento o doente mantinha-se febril, com profusa sudorese noturna, asténico e com mau estar geral apesar da terapêutica instituída desde a admissão com anti-inflamatório e posteriormente corticoesteróide e colchicina. Nesta altura são conhecidos os restantes resultados do IGRA (positivo) e do líquido pericárdico: ADA 81,3 UI/L (>20) e coloração de Ziehl-Neelsen com MT. 0 doente iniciou então esquema terapêutico tuberculostático com rifampicina 600mg QD, etambutol 1200mg QD, pirazinamida $1500 \mathrm{mg}$ QD e isoniazida $300 \mathrm{mg}$ QD. Cinco dias depois o doente encontrava-se subfebril (mais 2 dias e ficou sustentadamente apirético) e com melhoria do estado geral, descida acentuada dos parâmetros inflamatórios e regressão do derrame pericárdico (ecocardiograma: derrame pericárdico na região posterior de $2 \mathrm{~mm}$, pericárdio parietal com aspeto fibro-calcificado). Posteriormente, no exame cultural do líquido pericárdico houve crescimento de BAAR. 0 teste de sensibilidade aos tuberculostáticos não identificou resistências a nenhum fármaco. Prosseguiu-se 0 esquema iniciado durante 2 meses, seguido de 4 meses com rifampicina e isoniazida; associado a prednisolona e colchicina.

\section{Discussão}

0 tamponamento cardíaco é uma situação clinica potencialmente fatal e deve por isso ter uma abordagem clínica rápida e direcionada. Contudo, a sua baixa frequência e o fato de apresentar, na maior parte das vezes, uma história clinica 
inespecífica, exige um alto índice de suspeita clinica sempre que se avalia um doente com dispneia e dor torácica sem outra etiologia mais evidente 9 .

No presente caso o doente relatava uma história inespecífica com uma evolução subaguda e agravamento agudo, que é a apresentação mais habitual. Apresentava também o sintoma cardinal de pericardite que é a dor torácica tipo pleurítica de localização retroesternal que alivia com a anteversão do tronco e agrava com o decúbito dorsal e a inspiração ${ }^{1}$. Apesar de ser um sintoma cardinal, a dor torácica pode estar ausente, principalmente quando a evolução é indolente - 0 que acontece muitas vezes na pericardite com etiologia infeciosa por $\mathrm{MT}^{5}$. A história clínica era também pouco esclarecedora relativamente à etiologia, uma vez que 0 quadro constitucional é comum tanto na doença infeciosa, como na neoplásica e na autoimune, não excluindo nenhuma delas $^{1,2,4}$. 0 exame físico mostrava sinais de tamponamento cardíaco: hipotensão, hipofonese dos sons cardíacos e turgescência venosa jugular, classicamente denominados Tríade de Beck ${ }^{9}$. Um sinal patognomónico de pericardite é 0 atrito pericárdico na auscultação, que corresponde à fricção dos dois folhetos pericárdicos durante 0 movimento do coração. 0 atrito pericárdico está presente em 50 a $80 \%$ dos casos de pericardite e a sua ausência pode ser apenas por falta de experiência do médico, por não serem realizadas auscultações seriadas (uma vez que o som não está sempre presente), ou pelo facto de o derrame ser de grande volu$\mathrm{me}^{1,2} .0$ gold standard para a avaliação do pericárdio e da função cardíaca é o ecocardiograma (recomendação classe I de vários grupos de estudo: a American College of Cardiology (ACC), a American Heart Association (AHA), e a American Society of Echocardiography (ASE)), no entanto exames como 0 ECG e a RxT fornecem informações adicionais importantes. No ECG, as alterações descritas na literatura como típicas de pericardite são a baixa voltagem e alterações faseadas: inicialmente com elevação difusa do segmento ST-T com concavidade superior e ondas T apiculadas; posteriormente com segmento ST-T na linha isoelétrica com onda T achatada; cerca de duas semanas após com onda T invertida e por fim volta ao traçado pré-pericardite ${ }^{4}$. Neste caso não foram realizados ECG seriados, a baixa voltagem no exame da admissão é a única alteração que muitas das vezes se encontram e por isso a ausência das restantes alterações não nos permite excluir pericardite. Na RxT, as alterações que devemos procurar são as que o doente apresentava: aumento do ICT e uma silhueta cardíaca em balão (em doentes com patologia cardíaca prévia é essencial a comparação com exames prévios). A utilidade do ecocardiograma é transversal no diagnóstico das doenças do pericárdio, no acompanhamento da resposta terapêutica e na avaliação do prognóstico. Também é essencial como guia na drenagem do derrame pericárdico. Na imagem 0 derrame aparece como um espaço livre de ecos que pode ser medido e, segundo os critérios de Weitzman, ser classificado em: pequeno $(<10 \mathrm{~mm})$; moderado $(10-20 \mathrm{~mm})$ e grande (>20mm). Na situação de tamponamento podemos encontrar dilatação das cavas com pouca variação respiratória; colapso diastólico da parede livre do VD, AD, AE (auricula esquerda) e raramente do VE (ventrículo esquerdo); e no Doppler, aumento do fluxo tricúspide e redução do fluxo mitral na inspiração, e na expiração aumento do fluxo mitral de até $25 \%$ e redução do fluxo tricúspide. Outro sinal descrito como característico é o "swinging heart " que se refere ao movimento de rotação do coração para a esquerda, o que ocorre para além do movimento triangular do coração, produzindo um movimento semelhante a uma dança 4,9. A descrição do ecocardiograma do doente é condizente com sinais de grande derrame pericárdico em situação de pré-tamponamento. No caso de o derrame apresentar projecções "frondlike " e espessamento "porridge-like " deve-se suspeitar de $\mathrm{PT}^{5}$. Identificado o quadro de derrame pericárdico em pré-tamponamento, a questão que se impõe é a da realização de pericardiocentese. Esta técnica tem indicação classe I nos protocolos clínicos dos vários grupos de estudo (ACC, AHA, ACE) no caso do tamponamento cardíaco ou em qualquer derrame com mais de $20 \mathrm{~mm}$ medidos no ecocardiograma na diástole e de classe lla quando realizada apenas com objetivo diagnóstico ${ }^{9}$. É recomendada em todos os doentes em que houver suspeita de infeção por $\mathrm{MT}^{5,9}$. A pericardiocentese é uma técnica com riscos associados e cujas contraindicações são a disseção da aorta (absoluta), defeitos da coagulação e trombocitopenia $<50$ '000 plaque-

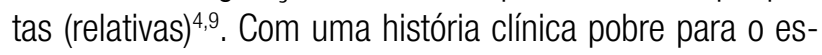
treitamento das possíveis etiologias, optou-se por fazer um estudo alargado do liquido: a observação macroscópica, 0 exame bioquímico (LDH, proteínas, glicose, ADA (valor diagnóstico e prognóstico) e auto-anticorpos (se suspeita de doença autoimune), o exame microbiológico (culturas para aeróbios, anaeróbios e fungos, coloração de Zhiehl-Neelson, exame cultural para BAAR e PCR de MT)e o exame citológico com pesquisa de células neoplásicas ${ }^{4,5}$. No caso da TP o líquido pericárdico é habitualmente um exsudado com aspeto hemático, níveis elevados de proteínas e leucocitose com predomínio de linfócitos ${ }^{5}$, tal como no caso apresentado. № entanto também as etiologias neoplásica e traumática podem ter um aspeto hemático e por isso a etiologia do derrame só foi confirmada posteriormente com o doseamento da ADA (mais sensível e específica no líquido pericárdico do que no soro) e a microbiologia que permitiu isolar 0 agente infecioso, o MT. 0 diagnóstico pode ainda ser feito por biopsia do pericárdio, no entanto vários estudos têm mostrado uma sensibilidade muito baixa e inferior às culturas do líquido pericárdico e à técnica de PCR, pelo que não é realizada por rotina a não ser que os restantes exames não estejam disponíveis ou os resultados sejam inconclusivos ${ }^{5}$. São várias as doenças sistémicas que podem condicionar uma pericardite, por isso a investigação diagnóstica não se pode esgotar no estudo do líquido pericárdico. 0 estudo analítico deve ter em conta a função renal e tiroideia, a autoimunidade no caso de haver essa suspeita, as serologias de acordo 
com o contexto epidemiológico do doente, ADA e ECA se suspeita de tuberculose ou sarcoidose, respetivamente. Posteriormente deve-se completar a investigação com outros exames de acordo com as hipóteses mais prováveis ${ }^{1,2,4,5}$. A prova de Mantoux tem visto a sua utilidade ser fortemente questionada principalmente nas zonas endémicas de tuberculose e nas populações com elevada taxa de imunização por $\mathrm{BCG}^{5,10}$. Os marcadores indiretos a pesquisar no líquido pericárdico para o diagnóstico de TP são a lisozima pericárdica, o interferão gama (INF- ) e a ADA. A última é a mais acessível e mais barata tendo um forte valor prognóstico para 0 desenvolvimento de pericardite constritiva ${ }^{5}$. 0 diagnóstico de TP pode classificar-se como definitivo quando 0 bacilo é isolado no líquido ou no tecido pericárdico ou quando são observados granulomas caseosos; ou como provável, quando há evidência de pericardite concomitantemente com tuberculose em outro órgão ou quando o líquido pericárdico é um exsudado com linfocitose e ADA elevada ou quando existe uma boa resposta a terapêutica tuberculostática ${ }^{5}$. Sistematizando, no caso de haver suspeita de tuberculose pericárdica, a investigação deve incluir: RxT para avaliar lesões sugestivas de tuberculose pulmonar; ecocardiograma; TC ou RMN (ressonância magnética nuclear) para excluir patologia neoplásica e avaliar a existência e localização de adenopatias que possam ser biopsadas; pesquisa direta de BAAR e exame cultural de micobactérias no líquido pericárdico (eventualmente também em amostras de expetoração, suco gástrico e urina); doseamento de ADA, lisozima pericárdica ou INF- no líquido pericárdico; biopsia pericárdica se evolução com mais de 3 semanas sem diagnóstico etiológico ${ }^{5}$. No que respeita ao tratamento, foi a introdução dos tuberculostáticos que alterou drasticamente a taxa de mortalidade de $80-90 \%$ para 8-17\%. No entanto não existe um verdadeiro consenso e os estudos sugerem que em zonas endémicas de tuberculose o tratamento dirigido deve ser iniciado mesmo quando o diagnóstico é apenas provável, ao contrário dos países não endémicos onde o tratamento fica reservado para os casos de diagnóstico definitivo. 0 esquema mais utilizado é o que aplicámos no caso descrito: 2 meses de etambutol, pirazinamida, rifampicina e isonizida, seguidos de mais 4 meses apenas com os dois últimos fárma$\cos ^{5}$. 0 uso de corticosteróides é controverso mas largamente utilizado, por haver alguma evidência de diminuição de mortalidade e da taxa de progressão para pericardite constritiva, para além de aumento da resposta aos tubercuIostáticos ${ }^{5,9}$. A pericardite tuberculosa não é então uma etiologia exclusiva dos doentes VIH positivos ou imunodeficientes em geral, das regiões endémicas ou dos doentes com tuberculose disseminada. Apesar da sua maior prevalência nestes grupos populacionais, não podemos excluí-la da investigação diagnóstica em grupos com menor incidência. A sua evolução indolente e semiologia inespecífica dificultam o diagnóstico, tornando extremamente importante a pesquisa de MT no líquido pericárdico por diferentes métodos disponíveis, bem como o recurso a outras metodologias indiretas como a determinação dos valores de ADA no soro e em particular no líquido pericárdico. No respeitante ao tratamento, mais estudos são necessários para consolidar a importância dos corticosteroides e a altura adequada para 0 início dos tuberculostáticos. Atualmente não existe indicação para iniciar tuberculostáticos de forma empírica, o que associado à demora da confirmação diagnóstica pode ser o suficiente para o desenvolvimento de sequelas cardíacas (como evidenciado neste caso), sendo a mais grave e mais comum a pericardite constritiva.

\section{Bibliografía}

1. Soler-Soler J, Permanyer-Miralda G, Sagristà-Sauleda J. A systematic diagnostic approach to primary acute pericardial disease. The Barcelona experience. Cardiol Clin. 1990; 8(4): 609-20.

2. Papadakis M, Mcphee S. Current medical diagnosis and treatment 2014 ("é este 0 título do capítulo?"). In: Editores. Título do libro. New York: Mc Graw Hill Education; ano. p $406-410$.

3. Imazio M, Spodick DH, Brucato A, Trinchero R, Adler Y. Controversial issues in the management of pericardial diseases. Circulation 2010; 121 (7): 916 - 928.

4. Maisch B, Seferovic PM, Ristic AD, Erbel R, Rienmüller R, Adyer Y. et al. Guidelines on the diagnosis and management of pericardial diseases executive summary; The Task force on the diagnosis and management of pericardial diseases of the European society of cardiology. Eur Heart J 2004; 25 (7): 587-610.

5. Mayosi BM, Burgess LJ, Doubell AF. Tuberculous pericarditis. Circulation 2005; 112 (23): 3608 - 16.

6. Programa Nacional da luta contra a tuberculose 2014, www.dgs.pt. "Dispoñible en: https://www.dgs.pt/outros-programas-e-projetos/paginas-de-sistema/saude-de-aa-z/tuberculose1.aspx"

7. Lopes AJ, Capone D, Mogami R, Tessarollo B, da Cunha DL, Capone RB et al. Tuberculose extrapulmonar: aspectos clínicos e de imagem. Pulmão RJ 2006; 15(4): 253-261.

8. [Stout Jason, et all. Tuberculosis pericarditis. UptoDate. Jan, 2014]. "Considerar eliminar esta referencia: UpToDate esixe autorización para reproducir o seu material noutra publicación".

9. Ristic AD, Imazio M, Adler Y, Anastasakis A, Badano LP, Brucato A et al. Triage strategy for urgent management of cardiac tamponade: a position statement of the European Society of Cardiology Working Group on Myocardial and Pericardial Diseases. Eur Heart J 2014; 35 (34): 2279-84.

10. Trautner BW, Darouiche RO. Tuberculous pericarditis: optimal diagnosis and management. Clin Infect Dis 2001; 33 (7): 954-61. 